\title{
Evidence-based professionalism in small specialist HE course management - reflexive thoughts on ongoing
}

\author{
research
}

\author{
NIEKY VAN VEGGEL \\ Faculty of Health, Social Care and Education, Anglia Ruskin University, Chelmsford, UK. \\ Writtle University College, Chelmsford, UK.
}

This paper outlines evidence-based practice in the context of professionalism, and highlights the contribution evidence-based practice can make to the professional practice of higher education course managers. Implications of the changing HE landscape for the status of academics as professionals are reviewed, and evidence-based practice is proposed as a solution for both enhanced course management and to remedy perceived deprofessionalisation. Finally, questions regarding researching professional practice within one's own institution are addressed.

Keywords: HE course management, evidence-based practice, professionalism, practice

\section{Introduction}

I am a senior lecturer and course manager in bioveterinary science at a small specialist landbased higher education institution (HEI) in the Eastern region of the UK. Although the institution is an $\mathrm{HEl}$, it also contains a significant contingent of Further Education (FE) students across various land-based courses. In the current academic year, the FE contingent is larger in numbers than the HE contingent, but the HE students bring in more funding than their FE counterparts, which leads to an interesting mix of priorities. Add to this mix a predominantly FE focused senior management team which has limited interest in fully developing Higher Education and its research ethos, and the notions of professionalism in academia and professional academic practice are precarious and cause significantly conflicting attitudes between management and HE teaching staff. These types of conflict surrounding academic 
professionalism are well known in higher education and shared by many higher education institutions.

The purpose of this paper is to explore in this context professionalism and professional practice in course management at a small specialist $\mathrm{HEI}$, with particular emphasis on the contribution evidence-based practice can make to enhancing professionalism. It does this by first evaluating how the terms "professional", "professionalism" and "professional practice" fit into higher education, followed by a review of evidence-based practice in higher education and a discussion on how evidence-based practice can enhance higher education course management. Finally, the potential impact of professional research into evidence-based HE course management on policy and practice in higher education will be assessed, taking into account ethical considerations, responsibility and professional accountability.

\section{Professional, professionalism and professional practice}

Some of the issues with defining "profession", "professional" and "professionalism" originate from the very limited consensus about the meaning of these terms (Fox, 1992). Traditionally, the term "profession" was used to refer to occupations such as doctor or lawyer. However, over time, this term has become much more flexible and inclusive. The criteria for an occupation becoming a profession have shifted (Evans, 2008) and "profession" is now often used to describe any occupation which requires an advanced degree of training or education (Fulton, Kuit, Sanders, \& Smith, 2013: 26).

Most interpretations of professionalism define it as a view of the externally set boundaries of the collective remit and responsibility of a profession (Evans, 2008). Indeed, according to Carr (2000), there are five dimensions to professionalism: provision of an important public service, an existence of the theoretical and practical expertise, a distinct ethical code of practice, a regulatory organisation, and a high degree of individual autonomy. These dimensions are recognised by Wilson et al. (2013), who define a professional as someone who exercises specialist knowledge and skills with judgement, who identifies as a member of a selfgoverning community founded on shared practices and values, and who has a sense of responsibility and service to the wider community. Additionally, Hampton, Wolf, Albinsson 
and McQuitty (2009) describe the requirement for a certification of licensing process as an attribute of a profession. Due to the distinct similarities of these definitions, it could therefore be concluded that a professional is someone who practices professionalism.

This definition can be further expanded to include an embodiment of a principled, ethical and responsible approach to work (Archer, 2008) and the need to engage with professional development (Peel, 2005), although it could be argued that these concepts are inherently covered through abiding by a responsible code of practice, and aligning with a regulatory or governing organisation.

It is interesting to investigate whether all dimensions of professionalism carry equal value, and whether this value changes over time or per profession. Especially since there is no single definition of profession and professionalism, it is hard to argue that all attributes of a professional are equal. For example, many of the more traditional professions (e.g. medicine or law) require a professional to possess a license to practice (Hampton et al., 2009), in addition to postgraduate level of specialist training. However, more recent professions might have only a license to practice without the need for postgraduate training (e.g. nursing) or have no need for a license to practice, but do require postgraduate level training (e.g. HE academics). I would argue that neither nurses nor academics are any less professional than doctors or lawyers. Furthermore, registration with and regulation by a professional body might be voluntary and not a requirement for practice, or it might be essential (e.g. membership of The Royal College of Veterinary Surgeons as a requirement to practice veterinary medicine in the UK). Does that make veterinary medicine more worthy of the status of profession than academia? Or does voluntarily subscribing to professional regulatory standards imply a higher form of professionalism than mandatory subscription? These arguments illustrate the complex and fluid nature of professions and professionalism in which not all attributes may carry equal importance to all professions, or even professionals. From a personal professional perspective I agree with Churchman (2002) and Feather (2010) who identify academics as professionals on the basis that they very much preoccupied and satisfied with the intrinsic rewards of academic work itself, and hold a postgraduate 
qualification, are regarded an expert in their field, are given autonomy to conduct research and disseminate outcomes via teaching and publications.

Although subject knowledge could be seen as the core specialist skill of a higher education (HE) professional (Feather, 2014), there is the additional skill and knowledge regarding teaching, learning and assessment which allows an individual to identify as a teaching practitioner who aligns with practices and values set by a community of fellow practitioners and overarching institutions such as the Higher Education Academy (HEA), the Quality Assurance Agency for Higher Education (QAA) and the new Office for Students and who feels responsible for sharing knowledge with students, fellow academics and the general public through a range of activities.

As an HE lecturer, I identify with both a subject-specific community and a teaching-specific community and arguably there is a fair degree of overlap due to the nature of higher education. For my subject-specific role I hold professional registration as a Chartered Biologist with the Royal Society of Biology, Registered Scientist with The Science Council, and European Professional Biologist with the European Countries Biologists Association. Although these are voluntary registrations, and as such have no direct influence on my ability to practice as a bioveterinary scientist, they do reflect my professionalism because maintaining these registrations requires adherence to professional body standards and codes of conduct (European Countries Biologists Association, 2013; Royal Society of Biology, 2016; The Science Council, 2016) which is an attribute of professionalism.

In my teaching role, I hold registration as a Fellow of the Higher Education Academy. Although again a voluntary registration, my employer does require new academic teaching staff to obtain fellowship within two years of starting in their role. However, it is fair to say this is not related to my professionalism, but rather to national benchmarking initiatives and perceived quality enhancement. 
As a Fellow I am required to adhere to the UK Professional Standards Framework [UKPSF] (Higher Education Academy, GuildHE, \& Universities UK, 2011). This framework addresses the previously mentioned overlap between my roles as it requires core knowledge of both subject-specific material and areas of teaching and learning. In a way my adherence to the UKPSF forms my expression of professionalism: my expertise, which Bottery and Wright (1997) identify as a key criterion for professionalism, is two-fold and covered by Core Knowledge K1-K6 of the UKPSF. In contrast, Activity A5 and Professional Value V3 and V4 could be seen as the transparency and susceptiveness to evaluation and analysis Farrugia (1996) says professionalism implies.

In addition to the above, the reality of teaching at my institution means that I am not only a lecturer. Due to the logistics of working in a small specialist $\mathrm{HEI}$, my role as course manager encompasses administrative, admissions, recruitment, marketing and management responsibilities. This makes me a 'new breed of academic' (Holbeche, 2012), and causes conflict in my professional practice: I have direct responsibility for improving a range of institutional and government metrics and success is measured by meeting targets and benchmarks. This managerialist approach (Nixon, Marks, Rowland, \& Walker, 2001) to HE removes some of the professional autonomy described by Wilson (2013) and means I am often stuck between what Harris (2005) describes as the 'economy of performance' and the 'ecology of practice'. In addition, the relative overrepresentation of an institutional FE mindset means I regularly experience issues described by HE in FE professionals such as large teaching loads (18-20 hours per week), little support for developing a research profile (Andrew Wilson \& Wilson, 2011), the belief that anyone can teach across all levels, and complying with the very target driven top-down controlled ethos of FE (Turner, McKenzie, \& Stone, 2009). Especially this last issue, the loss of professional autonomy, sometimes leads me to question my professional status as an HE lecturer, and I am not alone. 


\section{Professionalism in modern higher education}

In modern-day higher education, two of the most contested aspects of professional practice are professional autonomy and regulation of professional standards. Professions have historically achieved a great measure of collegiate autonomy with regards to professional training, self-regulation, determination of competency and imparting of specialist knowledge (Beck \& Young, 2005). In line with other professions, university academics enjoyed various degrees of self-regulation until the early 2000s, with an emphasis on service and trust (Milliken, 2004).

Various authors argue that through the marketisation and postmodernisation of higher education, professional autonomy is being eroded and replaced with higher degrees of internal accountability and measurability (Feather, 2015; Harris, 2005). Since Snizek (1972) argues that autonomy is an inherent dimension of professionalism, it could be argued that higher education is becoming deprofessionalised in favour of managerialist and audit practices which measure performance and output and benchmark these metrics.

In a recently published whitepaper, the UK Department of Business, Innovation and Skills set out plans to create the Office for Students (OfS) (Department for Business, Innovation and Skills, 2016). One of the functions of the OfS will be to administer and regulate the Teaching Excellence Framework (TEF), which is the new framework used for benchmarking the teaching quality of higher education providers. This top-down regulation and benchmarking, and the effect it has of the competitiveness of an institution, will increase pressure on institutions to increase their standards. This is turn is likely to lead to performance management approaches to institutional management, which Deem (1998) calls 'new managerialism'. However, this more corporate style of management often leads to identity schisms in higher education, caused by the perceived loss of professional autonomy by academic staff (Milliken, 2004; Winter, 2009). Additionally, the increased accountability seems at odds with the collective responsibility a profession possesses. Although accountability and transparency are important principles that academics should wholeheartedly embrace, Hoecht (2006) argues 
that 'the audit format adopted in the UK introduces a one-way accountability and provides "rituals of verification" instead of fostering trust, has high opportunity costs and may well be detrimental to innovative teaching and learning'. Although this argument mainly focussed on implementation of total quality management strategies by institutions in response to Quality Assurance Agency auditing, my experience of my employer's plans to engage with the TEF and to improve relevant metrics is that the loss of autonomy and increase in accountability are similar.

\section{Evidence-based professional practice in HE}

Evidence-based practice finds its roots in medicine. Strong developments in the 90 s led to the seminal definition of evidence-based medicine by Sackett et al. (1996): 'Evidence-based medicine is the conscientious, explicit and judicious use of current best evidence in making decisions about the individual patient'. Over time, and with the development of further allied health professions, this definition has evolved to reflect a greater number of health care professionals. The 2005 Sicily statement on evidence-based practice defines EBP as decisions about health care based on the best available current and valid evidence (Dawes et al., 2005). However, common assumption is that "best evidence" is quantitative by nature, with the meta-analysis of randomised controlled trials being the gold standard (Rycroft-Malone et al., 2004).

This narrow view of what constitutes evidence has been criticised as being exclusionary (Holmes, Murray, Perron, \& Rail, 2006) and disregards the interaction between research evidence and practitioner-generated evidence (Upshur, 1999). Morrell and Learmonth (2015) quite rightly argue that this attitude towards evidence is not limited to health care: even though Barends et al. (2014) inclusively state that in evidence-based management all evidence, regardless of its source, may be included if found trustworthy and relevant, the authors then go on to value positivistic research characteristics higher than phenomenological research characteristics. This concern is shared by Davies (1999) who notes that the relevance of education research depends greatly on what questions are asked 
in what context and what the practical application is, and by Morrison (2001), who argue that the randomised controlled trial is not automatically the ideal solution.

More recently, Biesta (2010) proposed to move away from evidence-based education because of various deficits associated with the methodology. However, his arguments were mainly based on a narrow interpretation of evidence-based practice and philosophical in nature. Therefore, I still am in favour of using an evidence-based practice approach to support decision making and would argue these are only perceived rather than actual deficits. I agree with Wiseman (2010): if the most appropriate evidence is used in an appropriate way, quality of education and student experience will benefit. In light of this, a more suitable definition of evidence is required, given that education and education management research is often multidisciplinary and/or cross-disciplinary.

The proposed definition of evidence by Rycroft-Malone et al. (2004) 'Evidence is the knowledge derived from a variety of sources that has been subjected to testing and has found to be credible' appears most inclusive and can easily be applied to HE course management. Indeed, where these authors list evidence bases for health care as "Research, Clinical experience, Patients, clients and carers and Local context and environment", evidence bases for HE course managers can be adapted without much trouble to "Research, Teaching and management experience, Students and (academic) staff and Local context and environment".

This more inclusive approach to what constitutes evidences is supported by Noyes et al. (2011) who argue that evidence from qualitative studies can play an important role in adding value to systematic reviews for policy, practice and consumer decision making. Furthermore, these authors find there are many qualitative methods of evidence synthesis that are appropriate to the aims and scope of a Cochrane systematic review. Therefore, rather than focussing on meta-analysis of randomised controlled trials, it is perhaps more appropriate to widen the scope and consider systematic reviews compiled from high quality original research of mixed methodology the golden standard for evidence-based decision making in education and education management. 
The traditional definition of evidence-based practice also does not consider practice-based evidence. Where evidence-based practice traditionally seeks to answer questions of a causal nature (Does intervention $X_{1}$ compared to intervention $X_{2}$ cause $Y$ in $Z$ ?), practice-based evidence, or evidence generated from professional experience and local data, seeks answers for complex real-life multi-system questions (How does adding $X$ intervention alter the complex multi-level system $Y$ of institution/course/student $Z$ before me?) (Swisher, 2010). Indeed, it is the dismissal of practice-based professional knowledge as a lower ranked form of evidence which drives the majority of opposition to implementing EBP methods in fields such as medicine (Tanenbaum, 1999), social work (Gibbs \& Gambrill, 2002) and education (Biesta, 2010).

At first sight, the traditional hierarchy of evidence (see figure $1 \mathrm{~A}$ ) does seem to suggest that professional practice-based knowledge is a form of evidence of little value, and the systematic review and randomised-controlled trial are far superior. However, a recently published alternative metaphor (Arlt \& Heuwieser, 2016) supports the notion of practice-based evidence as part of the "truth" (figure 1B). Although this metaphor still ranks professional knowledge or opinion lowest, it is now at least included. Furthermore, as argued by RycroftMalone and colleagues (2014) all knowledge which is subjected to testing and found credible forms evidence. Therefore, I argue practice-based evidence can, and should, be considered as relevant evidence as long as it holds up to some form of testing or contributes to a bigger evidence-base. Finally, in cases where practice-based evidence is the only available evidence, it automatically becomes the best-available evidence, thus meeting the threshold for inclusion in decision-making processes (Peile, 2004). 
A

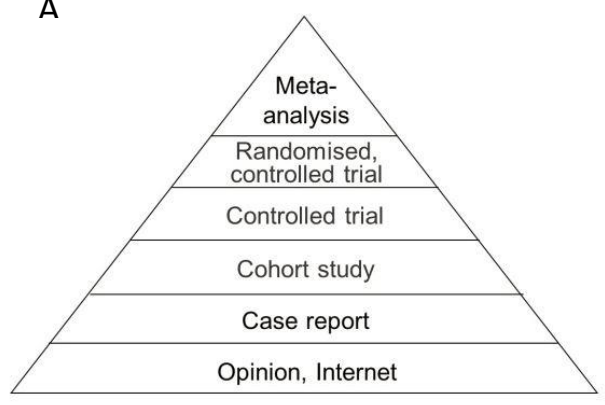

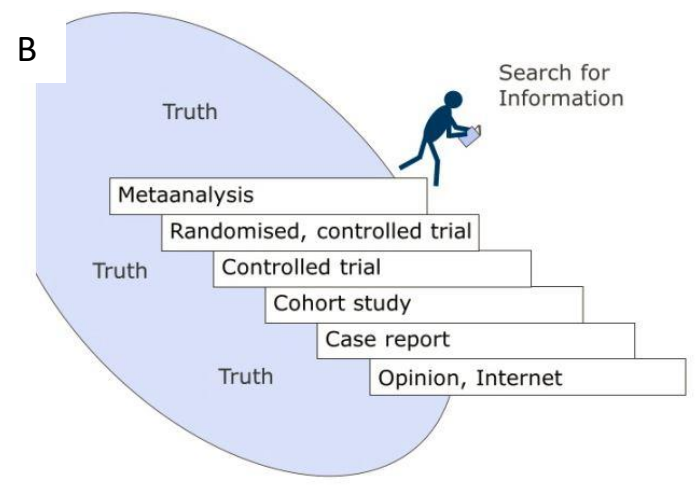

Figure 1: The traditional pyramid of evidence (A) vs. a proposed staircase of evidence (B) (Arlt \& Heuwieser, 2016)

\section{Evidence-based practice as a form of professionalism}

It is the more holistic approach to evidence-based practice as proposed by Rycroft-Malone et al. (2004) which makes it applicable to the professional practitioner. The integration and implementation of research evidence, institutional evidence and stake-holder evidence in a professional practice-based context like higher education requires the researcher to be fully immersed in their environment, whilst at the same time they must be aware of the bigger picture and supra-local context. Not only does the professional need to be proficient in their chosen subject to make independent decisions, they also need to be able to make use of relevant evidence to support their decision-making and accountability within the profession and the employing institution. I would therefore argue that rather than undermining the status of a professional, evidence-based practice enhances it by supporting the individual autonomy and by expanding the theoretical and practical expertise which Carr (2000) attribute to professionals. Furthermore, the structure offered by evidence-based practice supports the transparency and susceptiveness to internal and external evaluation and analysis of professionalism described by Farrugia (1996). In UK higher education, with the new benchmarking frameworks requiring ever more use of various forms of evidence to support multiple levels of accountability (e.g. internal institutional audits, QAA scrutiny, TEF reports, professional body requirements), evidence-based practice can therefore lead to a new dimension in professionalism and professional practice. 
In the context of social work practice, Otto, Polutta and Ziegler (2009: 477) conclude that evidence-based professionalism is based on 'empirically informed yet reflexively contextualized processes, through combining scientific evidence with modelling of individual response behaviour and of processes of broader social change'. I would argue that this understanding of professionalism aligns with Wilson's more traditional notion that a professional has a sense of responsibility and service to the wider community (Anna Wilson et al., 2013). Certainly in my own professional practice as a bioveterinary scientist and course manager this sense of responsibility leads to me using various forms of evidence to support my decision making, for example regarding maths support provision. During teaching sessions, I noticed a distinct lack of numeracy and maths confidence in my undergraduate students. After reading up on the matter and investigating institutional admissions and performance data, I implemented a small group tutorial system at course level, supported with institutional funding, and thoroughly evaluated it. This evaluation showed the tutorial system was successful.

Although I could have stopped there, I felt my responsibility to the wider bioscience community required this evaluation to be disseminated, so I chose to write it up for publication in an open access journal so that others could benefit from it free of charge. In this particular scenario, I not only used available evidence to determine an individualised solution to an institutional issue, but I also disseminated practice-based evidence which contributed to the understanding of the biomaths support needs of a changing undergraduate student population. This approach exemplifies how professionalism and evidence-based practice complement each other in my professional practice. It is this complementary nature of professionalism and evidence-based practice which lead me to believe there are gains to be made in the use of evidence-based practice methods by $\mathrm{HE}$ course managers. 


\section{Opportunities and challenges for research into evidence-based practice by course managers in $\mathrm{HE}$}

The use of routinely collected institutional data in combination with research data and stakeholder data would meet all the criteria for evidence-based decision making. It is currently unknown how course managers in small specialist institutions make decisions that affect metrics used for benchmarking, but the changing nature of higher education in the UK towards corporate managerialist management models (Churchman \& King, 2009) mean rankings and league tables are becoming ever more important (Gunn \& Fisk, 2013). For small specialist institutions like minie who lack the data processing units of large universities, doing well will become a challenge. The onus will be on academic staff to find and utilise data to inform decisions. Therefore, a greater understanding of how evidence-based practice can support and possibly simplify course management decision making would be useful not only for course managers themselves, but also for the institution and for the student experience. At the institutional level evidence-based decision making would provide an evidence trail for external and internal audits, and could inform quality enhancement and student experience initiatives, which would then positively impact on previously mentioned metrics used in $\mathrm{HE}$ benchmarks. For academic course managers, evidence-based practice can lead to a new sense of professionalism, because a new professional identity (Beck \& Young, 2005) can now be supported with evidence.

Although the application of evidence-based practice to higher education course management forms a logical subject for professional research, investigating current practice in one's place of work comes with challenges. Insider research is specific research by members of organisations and communities in and on their own organisations. Mercer (2007) argues that the theoretical insider/outsider dichotomy is actually a continuum with multiple dimensions and one is never completely an insider or outsider. This is apparent in the relation between my roles in the institution and the professional research: As a course manager I am an insider amongst course managers, however, in my role as a bioveterinary science academic I am an outsider for the same group. At the same time, I will be an insider to the institution. In practice, my identity as insider or outsider depends on what I am doing at the time, and I will 
need to carefully communicate my status to research participants to ensure they are fully informed throughout the research process.

The main advantage of insider research is primary access to actors and events, which allows for shaping to the research programme and will lead to a deeper understanding of outcomes. This has to be weighed against the disadvantages: own preconceptions and informant preconceptions (Brannick and Coghlan, 2007; Mercer, 2007). Additionally, the fine balance between the organisational role and the researcher role of the researcher can cause difficulty when it comes to confidentiality and institutional politics (Humphrey, 2013).

Perceived power differentials may exist between the researcher and the researched, and preformed expectations may lead to interview bias (Trowler, 2011) and consequently biased research outcomes. Ethical issues also arise. For example, if evidence-based practice methods in HE course management become the new gold standard, does not using evidence-based practice methods make a course manager less professional or less good at their job? This question illustrates the sensitivity of researching organisational change as an insider which will need careful consideration.

Political sensitivities between departments or even colleagues could affect the research, the researcher and the researched. The audience in an HE institution is four-fold: institutional management, students, colleagues and the outside world. It will be important to manage expectations, as research outcomes might not align with the agenda of all audience groups and could be perceived as politicised. The researcher therefore has to recognise the strategic priorities of the institution (Lofthouse, Hall, \& Wall, 2012), as well as the professional identity of colleagues and the perception of the research amongst students and the outside world. Finally, it will be imperative the researcher can convince colleagues of the value of the research in order to receive meaningful participation. 
As part of my current subject-specific role I am driving a departmental initiative to promote the use of systematic reviews for undergraduate dissertations. This includes delivering staff development sessions on this method, and I am aware that not all colleagues are convinced of the benefits of systematic reviews and evidence-based practice for undergraduate research. This causes two potential issues: firstly, colleagues will have a preconceived idea of my research into evidence-based practice methods and might be less receptive to implementation of the methods because of perceived lack of value. Indeed, Andrews and Lemons (2015) found that bioscience academics prioritise personal experience over empirical evidence when making teaching decisions. Secondly, through my staff development sessions on evidence-based practice I have a direct impact on my colleagues' understanding of the subject, and therefore on my research. In doing this project I will have to be aware of my own position in the institution and in the research, and fully acknowledge my influence on the research outcomes.

\section{Conclusion}

This paper has outlined discussed evidence-based practice in the context of professionalism, and highlighted the contribution evidence-based practice can make to the professional practice of higher education course managers. Implications of the changing HE landscape for the status of academics as professionals have been reviewed, and evidence-based practice has been proposed as a solution for both enhanced course management and to remedy perceived deprofessionalisation. Finally, questions regarding researching professional practice within one's own institution have been clarified.

\section{Acknowledgements [11pt, bold]}

The author wishes to thank Dr Philip Howlett for useful discussion and guidance during the development of this work.

\section{References}


Andrews, T. C., \& Lemons, P. P. (2015). It's Personal: Biology Instructors Prioritize Personal Evidence over Empirical Evidence in Teaching Decisions. CBE-Life Sciences Education, 14(1), ar7.

https://doi.org/10.1187/cbe.14-05-0084

Archer, L. (2008). Younger academics' constructions of 'authenticity', 'success' and professional identity. Studies in Higher Education, 33(4), 385-403. https://doi.org/10.1080/03075070802211729

Arlt, S. P., \& Heuwieser, W. (2016). The Staircase of Evidence - a New Metaphor Displaying the Core Principles of Evidence-based Veterinary Medicine. Veterinary Evidence, 1(1), 10.18849/ve.v1i1.18.g28. https://doi.org/10.18849/ve.v1i1.18

Barends, E., Rousseau, D. M., \& Briner, R. B. (2014). Evidence-based Management: The basic principles. Amsterdam: Center for Evidence-based Management. Retrieved from http://www.cebma.org/wp-content/uploads/Evidence-Based-Practice-The-Basic-Principles-vs-Dec2015.pdf

Beck, J., \& Young, M. F. D. (2005). The assault on the professions and the restructuring of academic and professional identities: a Bernsteinian analysis. British Journal of Sociology of Education, 26(2), 183-197. https://doi.org/10.1080/0142569042000294165

Biesta, G. J. J. (2010). Why 'What Works' Still Won't Work: From Evidence-Based Education to ValueBased Education. Studies in Philosophy and Education, 29(5), 491-503.

https://doi.org/10.1007/s11217-010-9191-x

Bottery, M., \& Wright, N. (1997). Impoverishing a sense of professionalism. Educational Management and Administration, 25(1), 7-24.

Carr, D. (2000). Professionalism and Ethics in Teaching. London: Routledge.

Churchman, D. (2002). Voices of the academy: academics' responses to the corporatizing of academia. Critical Perspectives on Accounting, 13(5-6), 643-656.

https://doi.org/10.1006/cpac.2002.0564

Churchman, D., \& King, S. (2009). Academic practice in transition: hidden stories of academic identities. Teaching in Higher Education, 14(5), 507-516.

https://doi.org/10.1080/13562510903186675

Davies, P. (1999). What is Evidence-based Education? British Journal of Educational Studies, 47(2), 108-121. https://doi.org/10.1111/1467-8527.00106

Dawes, M., Summerskill, W., Glasziou, P., Cartabellotta, A., Martin, J., Hopayian, K., ... Osborne, J. (2005). Sicily statement on evidence-based practice. BMC Medical Education, 5, 1. https://doi.org/10.1186/1472-6920-5-1

Deem, R. (1998). 'New managerialism' and higher education: The management of performances and cultures in universities in the United Kingdom. International Studies in Sociology of Education, 8(1), 47-70. https://doi.org/10.1080/0962021980020014 
Department for Business, Innovation and Skills. (2016). Success as a knowledge economy: teaching excellence, social mobility \& student choice. London: Her Majesty's Stationery Office.

European Countries Biologists Association. (2013). EurProBiol Code of Conduct. Retrieved 26 January 2017, from http://www.eurprobiol.eu/index.php/code-of-conduct/code-of-conduct/

Evans, L. (2008). Professionalism, Professionality and the Development of Education Professionals. British Journal of Educational Studies, 56(1), 20-38. https://doi.org/10.1111/j.14678527.2007.00392.x

Farrugia, C. (1996). A continuing professional development model for quality assurance in higher education. Quality Assurance in Education, 4(2), 28-34.

https://doi.org/10.1108/09684889610116030

Feather, D. (2010). A whisper of academic identity: an HE in FE perspective. Research in PostCompulsory Education, 15(2), 189-204.

Feather, D. (2014). Professionalism: doing a good job! Research in Post-Compulsory Education, 19(1), 107-118. https://doi.org/10.1080/13596748.2014.872940

Feather, D. (2015). An alternative proposition to Lewis' views on the 'Constructions of professional identity in a dynamic higher education sector'. Research in Post-Compulsory Education, 20(3), 324343. https://doi.org/10.1080/13596748.2015.1063300

Fox, C. J. (1992). What do we Mean When we Say 'Professionalism?': A Language Usage Analysis for Public Administration. The American Review of Public Administration, 22(1), 1-17.

https://doi.org/10.1177/027507409202200101

Fulton, J., Kuit, J., Sanders, G., \& Smith, P. (2013). The Professional Doctorate. Basingstoke: Palgrave Macmillan.

Gibbs, L., \& Gambrill, E. (2002). Evidence-Based Practice: Counterarguments to Objections. Research on Social Work Practice, 12(3), 452-476. https://doi.org/10.1177/1049731502012003007

Gunn, V., \& Fisk, A. (2013). Considering teaching excellence in higher education: 2007-2013: a literature review since the CHERI Report 2007 (HEA Research Series) (p. 60). Heslington: Higher Education Academy. Retrieved from http://eprints.gla.ac.uk/87987/1/87987.pdf

Hampton, G. M., Wolf, M., Albinsson, P. A., \& McQuitty, S. (2009). Market orientation and professionalism in higher education. Academy of Educational Leadership Journal, 13(1), 87-102.

Harris, S. (2005). Rethinking academic identities in neo-liberal times. Teaching in Higher Education, 10(4), 421-433. https://doi.org/10.1080/13562510500238986

Higher Education Academy, GuildHE, \& Universities UK. (2011). The UK Professional Standards Framework for teaching and supporting learning in higher education (p. 8). Higher Education Academy. Retrieved from https://www.heacademy.ac.uk/sites/default/files/downloads/ukpsf_2011_english.pdf 
Hoecht, A. (2006). Quality Assurance in UK Higher Education: Issues of Trust, Control, Professional Autonomy and Accountability. Higher Education, 51(4), 541-563. https://doi.org/10.1007/s10734004-2533-2

Holbeche, L. (2012). Changing times in UK universities. What difference can HR make? Universities Human Resources. Retrieved from

http://www.uhr.ac.uk/uploadedfiles/documents\%2FChanging\%2520times\%2520in\%2520UK\%2520u niversities\%2520(print\%2520version).pdf

Holmes, D., Murray, S. J., Perron, A., \& Rail, G. (2006). Deconstructing the evidence-based discourse in health sciences: truth, power and fascism. International Journal of Evidence-Based Healthcare, 4(3), 180-186. https://doi.org/10.1111/j.1479-6988.2006.00041.x

Humphrey, C. (2013). Dilemmas in doing insider research in professional education. Qualitative Social Work, 12(5), 572-586. https://doi.org/10.1177/1473325012446006

Lofthouse, R., Hall, E., \& Wall, K. (2012). Practitioner research. In A. R. J. Briggs, M. Coleman, \& M. Morrison (Eds.), Research methods in educational leadership and management (3rd edition, pp. 170187). London: Sage Publications.

Mercer, J. (2007). The challenges of insider research in educational institutions: wielding a doubleedged sword and resolving delicate dilemmas. Oxford Review of Education, 33(1), 1-17.

Milliken, J. (2004). Thematic reflections on higher education: Postmodernism versus professionalism in higher education. Higher Education in Europe, 29(1), 9-18.

https://doi.org/10.1080/03797720410001673265

Morrell, K., \& Learmonth, M. (2015). Against Evidence-Based Management, for Management Learning. Academy of Management Learning \& Education, 14(4), 520-533.

https://doi.org/10.5465/amle.2014.0346

Morrison, K. (2001). Randomised Controlled Trials for Evidence-based Education: Some Problems in Judging 'What Works'. Evaluation \& Research in Education, 15(2), 69-83.

https://doi.org/10.1080/09500790108666984

Nixon, J., Marks, A., Rowland, S., \& Walker, M. (2001). Towards a New Academic Professionalism: A manifesto of hope. British Journal of Sociology of Education, 22(2), 227-244.

https://doi.org/10.1080/01425690124202

Noyes, J., Popay, J., Pearson, A., Hannes, K., \& Booth, A. (2011). Qualitative research and Cochrane reviews. In J. P. T. Higgins \& S. Green (Eds.), Cochrane Handbook for Systematic Reviews of Interventions (version 5.1.0). The Cochrane Collaboration. Retrieved from http://handbook.cochrane.org/

Otto, H.-U., Polutta, A., \& Ziegler, H. (2009). Reflexive Professionalism as a Second Generation of Evidence-Based Practice: Some Considerations on the Special Issue 'What Works? Modernizing the Knowledge-Base of Social Work'. Research on Social Work Practice, 19(4), 472-478.

https://doi.org/10.1177/1049731509333200 
Peel, D. (2005). Dual professionalism: facing the challenges of continuing professional development in the workplace? Reflective Practice, 6(1), 123-140.

https://doi.org/10.1080/1462394042000326851

Peile, E. (2004). Reflections from medical practice: balancing evidence-based practice with practicebased evidence. In Evidence-Based Practice in Education (pp. 102-115). Maidenhead: Open University Press.

Royal Society of Biology. (2016). Chartered Biologist and Chartered Scientist guidance. Retrieved from https://www.rsb.org.uk/images/CBiolandCSciguidance.pdf

Rycroft-Malone, J., Seers, K., Titchen, A., Harvey, G., Kitson, A., \& McCormack, B. (2004). What counts as evidence in evidence-based practice? Journal of Advanced Nursing, 47(1), 81-90.

Sackett, D. L., Rosenberg, W. M. C., Gray, J. A. M., Haynes, R. B., \& Richardson, W. S. (1996). Evidence based medicine: what it is and what it isn't. BMJ, 312(7023), 71-72.

https://doi.org/10.1136/bmj.312.7023.71

Snizek, W. E. (1972). Hall's Professionalism Scale: An Empirical Reassessment. American Sociological Review, 37(1), 109. https://doi.org/10.2307/2093498

Swisher, A. K. (2010). Practice-Based Evidence. Cardiopulmonary Physical Therapy Journal, 21(2), 4.

Tanenbaum, S. J. (1999). Evidence and expertise: the challenge of the outcomes movement to medical professionalism. Academic Medicine, 74(7), 757-763.

The Science Council. (2016). Becoming a Registered Scientist (RSci). Retrieved from http://sciencecouncil.org/web/wp-content/uploads/2016/04/RSci-Competence-report-guidanceedited.pdf

Trowler, P. (2011). Doing Insider Research in Universities. Lancaster: CreateSpace Indepedent Publishing.

Turner, R., McKenzie, L., \& Stone, M. (2009). 'Square peg - round hole': the emerging professional identities of $\mathrm{HE}$ in FE lecturers working in a partner college network in south-west England. Research in Post-Compulsory Education, 14(4), 355-368. https://doi.org/10.1080/13596740903360919

Upshur, R. E. G. (1999). Priors and Prejudice. Theoretical Medicine and Bioethics, 20(4), 319-327. https://doi.org/10.1023/A:1009905701990

Wilson, A., Åkerlind, G., Walsh, B., Stevens, B., Turner, B., \& Shield, A. (2013). Making 'professionalism' meaningful to students in higher education. Studies in Higher Education, 38(8), 1222-1238. https://doi.org/10.1080/03075079.2013.833035

Wilson, A., \& Wilson, B. (2011). Pedagogy of the repressed: research and professionality within HE in FE. Research in Post-Compulsory Education, 16(4), 465-478.

https://doi.org/10.1080/13596748.2011.627169 
Winter, R. (2009). Academic manager or managed academic? Academic identity schisms in higher education. Journal of Higher Education Policy and Management, 31(2), 121-131.

https://doi.org/10.1080/13600800902825835

Wiseman, A. W. (2010). The Uses of Evidence for Educational Policymaking: Global Contexts and International Trends. Review of Research in Education, 34(1), 1-24.

https://doi.org/10.3102/0091732X09350472

\section{Notes on contributors}

\section{Nieky van Veggel}

Nieky is a senior lecturer and course manager in bioveterinary science at Writtle University College, and in the process of undertaking a Doctorate in Education (EdD) at Anglia Ruskin University. 